\title{
Pioneering the Internet in the Nineties - An Innovative Project Involving UK and Australian Schools
}

\author{
Angela Lecomber \\ Victoria University and See Differently \\ angelalseedifferently.com.au
}

\begin{abstract}
The author discusses the challenges and shifts of pedagogy in incorporating an innovative Project to link UK and Australian schools between 1996 and 1998. Despite the UK government's National Grid for Learning policy in 1997, only four schools (out of the total of 125 schools) in Sunderland, UK had a computer connected to the Internet. Schools still functioned as classrooms of the Industrial age.
\end{abstract}

Keywords: Science teaching, laboratory, Sunderland, Internet.

\section{Background}

In the nineties, I was a Secondary School Science teacher in a Girls Catholic School in Sunderland, in the North-East of England. This was a career change for me having previously been a COBOL programmer and systems analyst in a London Bank. Consequently I had a personal interest in the use of computers.

My experience was typical for teachers in the early nineties in Sunderland. There was no such thing as an ICT teacher nor was there a subject called ICT. Subjects were taught strictly within the discipline with little if any cross-over with other subjects. For example, year 7 students covered Water and Energy in Science but the overlap into the separate subject of Geography was frowned upon.

There was one computer per science laboratory and this was used by the Head of Science to write reports and for the laboratory technician to record orders on supplies. It was only very occasionally used for students. If at all, it was used for the very brightest who had finished all the assigned work to access a CD-ROM disc which had some material on the subject being studied. In essence, the CD-ROM was a glorified Encyclopaedia with photos. Invariably a crowd would gather around the computer. There was no local area network (LAN) and computers were not connected to the Internet.

\subsection{Little Incentive to Explore the Use of the Computer in the Classroom}

Disappointingly, there was little incentive to alter curriculum planning and delivery to explore the use of computers to assist with delivering subjects. Although teachers were allowed the freedom of how material was delivered (exercises, homework and class activities that would suit the interest and aptitude of pupils), we had to cover the 
curriculum. There was nothing in the biology and chemistry curriculums that had any reference to the use of computers (or technology). It was puzzling to me that there was software (such as data logging tools, assorted CD-ROMs and floppy disks) in the laboratory cupboard, most still unopened in their packaging.

When I attempted to explore this, I was often reminded by the Head of Biology that it was a waste of time to bother with the computer or experiment with software. The Head of Science was a little ambivalent and did not mind if I dabbled with the software. My superiors considered computers to take time away from the valuable task of teaching. In any event, I would get no support from the laboratory technician.

Assignments were handwritten and desk-top publishing with word processing programs was not available to students to use.

\section{Sunderland - Backwater or Typical of Cities in the UK?}

According to the Science Advisor who oversaw science throughout Sunderland from nursery to high school at the time, "the development of computer usage was behind that I had known in Leeds, probably because Leeds University, the Leeds Local Education Authority and the Yorkshire Region had been at the forefront of many developments in the UK."(Valerie Wood-Robinson, Jan 2014).

\subsection{Personal Reflections of a Science Advisor}

Valerie Wood-Robinson was Sunderland's Science Advisor from late 1993 to early 1997. She oversaw my teaching in Science and had previously been involved in seminal initiatives to use computers in education in the UK. Although 'seminal', many of the seeds fell on stony ground and others took a very long time to germinate, as the following observations indicate.

In the early 1980s, Valerie was asked to join a working group of teachers at Leeds University to devise or adapt school experiments to make use of a data logging tool called VELA (Versatile Laboratory Aid). VELA was a stand-alone data logger or could be connected to a BBC Microcomputer or other suitable computer to allow the downloading of data for analysis. She was on the group as a biology specialist to design sensing and data capture uses in biological experiments. In 1986 VELA was dispatched to four thousand teachers across the UK. However, there was a suspicion that the uptake by teachers was low. This was confirmed later when as Sunderland science advisor, and subsequently as an Inspector in other parts of England, she found VELAs in cupboards still in their packaging, never used.

In 1984, Valerie was invited, as Head of Science of one of the biggest schools in Leeds, to be the Leeds representative on a Regional Project involving eight Local Authorities in Yorkshire and supported by the large-scale national Microelectronics Project (MEP). Each representative was given a kit of about twenty different pieces of software for their school and after being shown how to use this was expected to cascade professional development (known as INSET sessions) to staff out of school hours. 
This Project started well until it was scuppered by a Teachers' Unions "work-torule" which forbade its members doing any in-service training or curriculum development at lunch times or after school. Responding to this directive, the teachers in schools in the Project refused to cooperate with the training and reporting. It is not known to what extent other Projects within the national MEP initiative suffered the same fate. Valerie has recently contacted the co-ordinator of the Project who recalled that it was also hampered by difficult relations between the MEP "people in London" and the organisers in Yorkshire. The coordinator wrote a report to MEP but it was never published. Consequently, in most of the Regional Project schools, the software was stored away in cupboards un-used.

Her first recollection of training in using computers in teaching were sessions provided, in the early eighties, by the ASE (Association for Science Education) in conjunction with Leeds Education Authority Teachers' Centre. Teachers attended in their own time after school or at weekends, so only enthusiasts would be there. Training was also provided by LEAs (Local Education Authorities) in school time but usually only the Head of Science would be allowed to attend, and only if the Head teacher thought the topic was worthwhile and many did not. Courses were also run by some Universities. Again, a limited number of teachers would attend, and schools often thought it was just for Physics teachers.

Valerie relates being on a Project supported by a UK government national initiative TVEI (Technical and Vocational Education Initiative announced in 1982) focussed on the use of technology, with an emphasis on computers across the curriculum. There were cultural barriers as many secondary school teachers were entrenched in their subject allegiances and were reluctant to concede any territory to cross curricular interventions. Despite the intentions of TVEI to implement technology across the curriculum, this was derailed by heads of departments who viewed those with funding as empire builders.

She relates how in writing newsletters on behalf of the St William's Foundation Technology Education Project, she had only the simplest computer facilities provided to her even though the Project was funded from the TVEI. She used a minimal word processing programme and literally cut-and-pasted (scissors and glue), then photocopied. She appealed to teacher readers to ask if any who had desk-top publishing facilities would guest-edit issues of the newsletter, but none were forthcoming.

The cultural hurdles encountered by these Projects in which Valerie was involved elsewhere provide a context for the Sunderland Project described in the case study in this chapter.

\section{1 and ICT}

In 1991, the first World Wide Web page was created in the world and in that same year Margaret Thatcher had just stepped down as Prime Minister. Sunderland had the highest unemployment rate in the United Kingdom.

I was eager to exploit the potential for the Internet in revolutionising the way subjects were taught and to provide interest in finding new ways to use Information and 
Communications Technology (ICT) in the classroom. ICT refers to technological tools such as CD-ROM technology, interactive video technology and the Internet.

\section{6 - UK Government Urged to Make 'an Act of Faith'}

In 1996, the Stevenson Report 'ICT in UK Schools' produced by the independent ICT in School Commission for the UK Government justified why funding of ICT for education was necessary. The report stated that the claims made about the value of ICT for student learning outcomes were laudable and although these were not entirely proven, "... it is important that Government makes this act of faith and that we use technology rather than study it over the next decade" (Stevenson, 1996). The report suggested a framework for both primary and secondary schools: The Role of Government, Teacher Training, Software, External Networks, Hardware and Funding.

The report pointed to the commitment that the Australian Government was making by the year 2001: targeting a ratio of one computer for every 7.5 students and ICT used for all eight key learning areas at all year levels from pre-school to year 12 and for students of special needs.

\section{$5 \quad$ Sunderland - Teleport of the World}

Also in 1996, the local Sunderland council launched its City's Telematics Strategy. The strategy was to develop the City of Sunderland as a Teleport, the only one outside of London in the United Kingdom. A teleport is a port of electronic information that would link the community together: business, education providers, health authorities among sectors of the community.

With the potential for funding from the Sunderland Telematics Strategy, I responded with a compelling Business case. I proposed an innovative Project to pioneer the use of the Internet in schools with a view to engendering environmental citizenship. I had based this on suggestions made by Vockell and Brown (1992) that the computer was a technological tool that was able to support the education of schoolchildren to become citizens who are able to participate in social, civic and political processes and in some meaningful way further the values and beliefs that characterise active and involved citizens in a democratic society.

The Business case was approved with 36,000 Pounds provided from the Telematics Strategy and Local Agenda 21 Environmental Action Plan. Furthermore the University of Sunderland offered me the opportunity to undertake a $\mathrm{PhD}$ study on the use of Internet in Schools with a focus on environmental citizenship.

There were ninety-seven state primary and seventeen state secondary schools in Sunderland but only four of them had a computer connected to the Internet. Consequently these four schools were selected to be part of the pilot. These were Hillview Junior, Springwell Dene, St Robert of Newminster Catholic and Washington School. A fifth school, Southmoor was selected based on their commitment to get computer connectivity by the end of 1997 . The University of Sunderland offered me the support of a part time technician to work with five schools consisting of 40 teachers. 
It was disappointing that my own school (St Anthony's Catholic Girls school) were reluctant to be involved. There was no commitment to get connected to the Internet. There did not want to change tried and tested formulas for achieving academic results which at the time were the best in Sunderland. Perhaps and more likely the reason was the lack of confidence that the teachers had in their skills with ICT. Nevertheless I was compelled to resign from teaching to manage this innovative Project.

In 1997, Sunderland was heralded the 'Teleport of the World'. Tony Blair became Prime Minister that year and spearheaded the UK Government's Consultation Paper 'Connecting the Learning Society'. This paper explained the Government's proposals for securing the benefits of advanced network technologies for education and lifelong learning.

By the publication of this Consultation Paper, there were 32,000 state and independent schools with over 450,000 teachers and over 9 million pupils in the United Kingdom. Of these 6,000 had connected to the Internet and some 4,000 had installed local area networks of varying extents. The Times Newspaper reported that UK schools had the biggest 'take-up' rate in Europe on the Internet (17 Nov 1997).

Pilots were being pioneered and assessed throughout the country and my Project known as 'ICT for Environmental Citizenship' was one of them.

\section{The Project}

The promotional literature for the Project described the objective as:

'To use computers in schools to communicate with each other, across the country and the rest of the world, to learn more about the environment and the ways in which they can work with one another to preserve it.'

I was keen to find partner schools in another part of the English speaking world. This would promote novelty for the schoolchildren and promote cross-country partnerships in exploring the new Internet capability. The Association of Science Education provided funding to link schools in Australia with the existing group of five selected schools. Australia was a focus because it was English speaking and had similarities in the Year 7 and 8 Environmental Curriculum. Australia's distance from the UK would be of interest in exploring collaborative learning across the globe.

I piloted a twinned collaborative curriculum between Hillview Junior School, Sunderland, UK and Greensborough Primary School, Melbourne, Australia. Both schools had a committed Head Teacher, a network of ten computers with a ratio of one computer to three schoolchildren available at one site or classroom and at least one Internet address specific to the Project. They both had a supportive co-ordinating teacher, technical support, a commitment to the Project throughout the year and an interdisciplinary approach to the Project.

In fact Greensborough Primary was more equipped than Hillview Junior with sixteen networked computers in their computer labs, largely through raising their own funding and getting parents to install the necessary wiring. 


\section{The Journey}

\subsection{Internet - A Galaxy of Trashcans}

The Project targeted Year 7 and Year 8 students and had a ten stage plan. The first three stages of the Project involved engaging the head teachers and environmental subject specialists of the schools to ensure that they were fully on board and that they were interested in exploring a new way of incorporating the Internet into the environmental curriculum. At the time, there was a great deal of scepticism of the authenticity of material on websites and validity for education since anyone could create material. One head-teacher described the Internet as 'a galaxy of trashcans'. This was the very narrow view of its capability other than the capacity for electronic mail. One of my challenges was to find sites that were authentic, accurate and attractive for teachers and students to use.

Environmental subject specialists were not entirely convinced of the Internet's value and would have preferred the same allocated time to taking their pupils to look at the local pond-life, for example. Other teachers who were supportive were interested in the ICT technology but not interested in using it for environmental curriculum. They were the school's first appointed ICT teachers who invariably had a technical bias.

The website for the Project (http://cei/sunderland.ac.uk/schools) was developed largely using 'HotDog' one of very few HTML editors on the market at the time. It was easy to use and the teachers and students learned to use this too.

This central website would provide ideas for teachers about what they could do with the Internet within the curriculum and provide sample ways in which schoolchildren could use it. I had to also provide them with accredited websites and to network with others. The website was to be a co-ordinating platform and 'window' to an observer of the Project. The idea was to get each participant teacher to create a web page reflecting their work around a particular part of the curriculum.

\subsection{Overcoming Blandness and Waiting Periods}

The cost of using on-line services (not the fixed subscription fee) had not been established. High speed transmission was not available which affected waiting periods for a webpage to download. ISDN2 lines were used. However if a total page size of a home page was up to $30 \mathrm{k}$, then it would take 30 seconds to download.

The challenge to be overcome was the perception that children had of websites. In 1996, the World Wide Web pages did not have the sophistication and interactivity as they do today. Web pages were uninteresting and bland. They were not designed to be read or used by children. The pages were unappealing and were not designed for children with an accessible, lively and informal format to encourage them to send emails and to discuss their work. Web pages did not offer the differentiation for the different audiences and interests as they do today. The design of websites was at its infancy and good design principles were not used to make presentation of material appealing to young people. 


\subsection{Technologically Barren}

By January 1997, the schools in the Project had a dedicated computer room with access to the Internet. However it was disruptive if children were allowed out of the classroom to use the computer room. This could have been solved with extra telephone lines made available and connected to classrooms with extensions. However, schools were 'technologically barren' with any extra telephone lines going into the head teacher's or senior member of staff's office.

Most teachers in the five schools had to share electronic mail. There was no individual electronic mail. In two schools, there was only one address for the whole school. Problems existed on the Project because only one email address was used by all teachers and pupils. Hence in these cases, the co-ordinator of the Project would divert incoming messages to virtual files belonging to each of the participating teachers and their classrooms.

Teachers on the Project had to be taught the necessity of emptying their mailbox regularly, organising access to the electronic mail messages as soon as they came in. The importance of replying to messages within two days was a useful recommendation raised by the ICT teacher of one of the schools. Otherwise the momentum and the interest in the exchange is lost and subsequently the value in the collaborative partnership. For example, webpages were created about a particular environmental interest like reduction in the use of energy. Then this was shared by sending electronic mail in a purposeful way. Receiving feedback through electronic mail was valuable as it encouraged students to recall their work in a way different from the usual context. However if electronic mail took more than two days to get a response, then often interest waned in the collaboration.

\subsection{Politics of the Computer Room}

A curious problem was that of the 'blocker'. This was the teacher with ICT skills who would deliberately make access to the computer room difficult for other teachers e.g. keys were not available, passwords not made known, changes to software not explained. There was an underlying political agenda in a number of schools where those who were seen to be in charge of the new technology were not prepared to share knowledge readily and openly with their non-ICT literate colleagues. Typical complaints from non-ICT teachers would be "Cannot understand why the IT department have locked up the computer room. I am very keen on using computers and want pupils to have easy access. It is very frustrating as computers are rarely available to teachers, let alone pupils".

\subsection{Pedagogy}

With the fourth stage of the Project, I was challenged into fitting the use of the Internet into existing schemes of work used by the teachers. Even when the Internet was used in the pilot schools, the use of the Internet was 'tacked on' at the end of a unit of work rather than linking it within the schemes of work and what the teachers were 
already doing. The way in which the computer was used with schoolchildren was simply the mastery of basic skills of using the Internet. Pedagogy was still teachercentred and not student-centred.

Regrettably, there was little shift in pedagogy in those early days with the introduction of the Internet into the classroom. The computer was seen as a supplement to teacher-controlled activities rather than intrinsically part of it. Even though I had produced new material in order to refine and expand instructional strategies knowing that students would be on their own with the computer, technology had not yet influenced teaching styles.

There was the need to shift perceptions: from being 'fount of knowledge' to being a facilitator of student learning.

\subsection{Taking the Terror Out of ICT}

The fifth stage of the Project was to 'take the terror out of ICT' i.e. the challenge of developing the expertise and confidence of teachers in the use of the Internet.

With regard to the production of webpages, down-to-earth, user-friendly advice was provided including template webpages to assist and show how teachers could produce these offline. Classes were provided and support was available.

Teachers were shown how to bookmark sites before a lesson so as to direct pupils to a site quickly and allow them to navigate their way to the necessary pages. In addition, teachers were instructed on the mechanisms to avoid unsuitable websites. They were concerned about what personal information they could allow pupils to divulge over the Internet without putting themselves or others in 'danger'. Concerns about reports of children being abducted over the Internet had pre-occupied them. They sought guidelines and standards from the local education authority as to the standards of use of the World Wide Web and the Internet as a learning medium for schoolchildren.

Another consideration was that of online resources that were largely inaccessible to schoolchildren because of their reading ability. Teachers where guided to create simpler versions of the online resources and store these offline for access by their pupils as these were simpler to read.

Individual classes were encouraged to produce webpages and teachers were provided with ecological packages on disk and CD-ROM as springboards for new ideas and approaches. Teachers were also encouraged to develop their own material.

\subsection{Findings}

Although forty teachers undertook the personal training on the use of the Internet, few actually succeeded in accommodating the Project in their schemes of work. Most devoted only three lessons to the Project citing reasons such as lack of time and need to cover more pressing curriculum commitments. According to Valerie-Wood Robinson (2014), as an adviser she met resistance to using computers in schools on the justification that there was so much curriculum material and administrative procedures to cover, that there was no time for this innovation. 
In fact, many teachers were reluctant to accept the changes required, mainly due to fear of the unknown, and the fact that they (teachers) were less competent with computers than their pupils who were beginning to develop computer skills by playing games on home computers. This latter problem was not prevalent in Primary schools, and, although terrified of the new technology, most primary teachers were willing to give it a try in a whole school enterprise.

Towards the end of the Project in September 1998, some teachers were moving towards a more individualised model where the teacher assumed the role of facilitator and students made their own enquiries and engaged in collaborative activities. These teachers were invariably the experienced teachers in their field e.g. head of departments in geography, science and ICT. Perhaps heads of departments have more time to devote to innovative Projects. Perhaps they have nothing to prove in terms of their knowledge and more open to a shift in pedagogical approach: from 'founts of knowledge' to facilitators of learning. Whatever the reason, it was significant that those who were very familiar with the knowledge content of their specialisms were noticeably embracing ICT.

It was difficult enough to get teachers to use ICT, let alone for non-ICT subjects like environmental citizenship. The Project required a shift in teaching methods and styles to a student-centred approach. There was a lack of support for how to do this. Furthermore, teachers up until 1998, were not formally taught pedagogy (Times Education Supplement, 12th June 1998).

This Project made the following recommendations for both primary and secondary schools:

- $\quad$ Professional development of teachers in the use of ICT and student-centred pedagogy

- The need for regular support of teachers in the use of ICT in the classroom

- More work with Heads of Departments to ascertain where ICT fits into schemes of work

- The need to convince and support Head teachers and Heads of ICT to involve ICT in non-ICT subjects like environmental education.

\section{Conclusion}

Despite the rhetoric and objective of the UK Government in preparing schools for the twenty first century, in practice, they were still functioning as classrooms of the Industrial age. There were technological limitations and the lack of affordability in terms of connectivity to the Internet. However, probably the key factor in its lack of adoption in schools was the fear of using computers due to the lack of skills. Issues of shared ownership of computers and its place in the curriculum may have been underlying factors. In any event, there would need to be a shift in pedagogical approach from teachers as 'founts of knowledge' to 'teachers as facilitators of learning'. Nevertheless, computing in schools took off not because of educational initiatives but because teachers, as well as pupils, developed their skills in home computing. 
It was indeed a time of great promise for citizenship and hope for young people who felt that something different was happening in education to make the world a better place.

Acknowledgements. The author gratefully acknowledges the rich contribution of Valerie Wood-Robinson, Science Advisor (Inspector) for the City of Sunderland during the period 1993 to 1997.

The author also wishes to thank the opportunities afforded by those who supported this cutting-edge Internet Project. In particular the University of Sunderland (Dr Tony Alabaster), Sunderland Telematics Strategy, Local Agenda 21, the Association for Science Education and the teachers involved in the pilot schools both in the UK and Australia.

\section{References}

DfEE, Connecting the Learning Society. National Grid for Learning. Government's Consultation Paper (1997)

Stevenson, D.: Information and Communication Technology in UK Schools. Report by the Independent ICT in School Commission 1996/97 (1996)

Vockell, E., Brown, W.: The Computer in the Social Studies Curriculum. McGraw-Hill, California (1992)

Wood-Robinson, V.: Email communication to Angela Lecomber (2014) 